\title{
Posterior shoulder tightness and rotator cuff strength assessments in painful shoulders of amateur tennis players
}

\author{
Freddy B. Marcondes ${ }^{1,2}$, Julio F. de Jesus ${ }^{3,4}$, Flavio F. Bryk ${ }^{4,5}$, \\ Rodrigo A. de Vasconcelos ${ }^{2,6}$, Thiago Y. Fukuda ${ }^{5}$
}

\begin{abstract}
Background: Previous studies have shown a relationship between shoulder posterior capsule tightness and shoulder pain in overhead athletes. However, this relationship has not been studied in tennis players. Objectives: Assessment of the shoulder range of motion (ROM), strength and posterior capsule tightness of skilled amateur tennis players who had complaints of dominant shoulder pain in comparison with tennis players without pain. Method: Fortynine skilled amateur tennis players were distributed in 2 groups: Control Group $(n=22)$ and Painful Group ( $n=27)$. The first group was composed of asymptomatic subjects, and the second was composed of subjects with shoulder pain on the dominant side. These groups were evaluated to determine the dominant and non-dominant shoulder ROM (internal and external rotation), isometric shoulder strength (internal and external rotation) and posterior shoulder tightness by blind evaluators. Results: The ANOVA results indicated significant differences between the groups in the dominant shoulder ROM, posterior capsule tightness, external rotation strength and strength ratio $(\mathrm{p}<0.05)$. The intragroup analysis (dominant versus non-dominant) in the Painful Group displayed a significant difference for ROM, posterior capsule tightness and external rotation strength $(\mathrm{p}<0.05)$. Conclusions: The tennis players with pain in the dominant shoulder presented greater posterior capsule tightness, internal rotation deficit (ROM), external rotation gain (ROM) and deficits in external rotation strength than the tennis players without pain.
\end{abstract}

Keywords:physical therapy; rehabilitation; tennis; rotator cuff; Shoulder Impingement Syndrome.

HOW TO CITE THIS ARTICLE

Marcondes FB, Jesus JF, Bryk FF, Vasconcelos RA, Fukuda TY. Posterior shoulder tightness and rotator cuff strength assessments in painful shoulders of amateur tennis players. Braz J Phys Ther. 2013 Mar-Apr; 17(2):185-194. http://dx.doi.org/10.1590/ S1413-35552012005000079

\section{Introduction}

Tennis is a global sport, and there are more than 200 associated countries in the International Tennis Federation as well as similar, and it is represented by players of all ages. It is estimated that the injury rate in tennis is approximately 21.5 injuries per 1000 practice hours ${ }^{1,2}$. Tennis exposes these athletes to injuries, and the shoulder is the most injured joint ${ }^{1}$. Shoulder injuries, in general, lead to a restriction in tennis practice due to the high demand imposed on the shoulders during the execution of movement. The most common injuries among tennis players are SLAP (superior labrum anterior to posterior), multidirectional instabilities and posterior shoulder tightness ${ }^{3}$. Posterior shoulder tightness, described for the first time by Papas et al. ${ }^{4}$, causes a reduction in internal shoulder rotation and increases external shoulder rotation ${ }^{5,6}$. Because of these characteristics, some adaptations in scapula biomechanics occur that favour biomechanical problems that cause injuries in the overhead throwing shoulder.-9. Some studies have demonstrated posterior shoulder tightness in the athletes of several sports that require overhead motion $^{6-8}$. Nevertheless, it is still necessary to evaluate this dysfunction in tennis players because it is not uncommon to find these athletes unable to play tennis due to pain in their dominant shoulder ${ }^{3,10}$.

The biomechanical adaptations of the scapula increase an athlete's risk of developing musculotendinous injuries in the rotator cuff ${ }^{11}$. These adaptations include an increase in scapular protraction and anterior tilt, an increase in sternoclavicular elevation, a "dropped" scapula in rest position, and a reduction in scapular upward rotation ${ }^{6-9}$. Burkhart et al. described 3 clinically recognisable

\footnotetext{
${ }^{1}$ Departamento de Ortopedia e Traumatologia, Universidade Estadual de Campinas (UNICAMP), Campinas, SP, Brasil

${ }^{2}$ Núcleo de Estudos, Instituto Wilson Mello (IWM), Campinas, SP, Brasil

${ }^{3}$ Departamento de Ciências, Universidade Federal de São Paulo (UNIFESP/EPM), São Paulo, SP, Brasil

${ }^{4}$ Grupo Especializado em Reabilitação Funcional (GERF), São Paulo, SP, Brasil

${ }^{5}$ Departamento de Fisioterapia, Irmandade da Santa Casa de Misericórdia de São Paulo (ISCMSP), São Paulo, SP, Brasil

${ }^{6}$ Laboratório de Análise da Postura e Movimento Humano (LAPOMH), Universidade de São Paulo (USP), Ribeirão Preto, SP, Brasil

Received: 09/19/2012 Revised: 11/05/2012 Accepted: 11/20/2012
} 
patterns of scapular dyskinesis during the arm elevation: the type I pattern with inferior medial scapular border prominence, the type II pattern with medial scapular border prominence, and the type III pattern with superomedial scapular border prominence ${ }^{7}$. Furthermore, the rotator cuff, along with these biomechanical adaptations, can cause a posterosuperior dislocation of the humeral head during the slowdown phase, and this dislocation produces an internal impingement of subacromial joint structures ${ }^{5,6,12}$. There are some studies describing the thickening of the inferior glenohumeral ligament as an adaptive mechanism in overhead motion athletes due to repetitive movements. Despite these studies, the exact cause of this dysfunction is still unclear ${ }^{6,7}$; however, it is possible to clinically assess this dysfunction using the test described by Myers et al. ${ }^{10}$.

Due to alterations in shoulder biomechanics caused by posterior shoulder tightness in overhead motion athletes and the possibility of this dysfunction to promote injuries during the slowdown phase of the tennis serve, this dysfunction was evaluated. There are some studies that have demonstrated posterior shoulder tightness in overhead athletes ${ }^{6,9,10,13,14}$, and our goal was analyse whether these disorders would also be observed in amateur tennis players. Posterior shoulder tightness leads to changes in the rotation axis of the humeral head. This type of tightness moves the humeral head in the posterior and superior directions, thus promoting a reduction in internal rotation and an increase in the external rotation, which, in turn, generates an alteration in the athlete's $\mathrm{ROM}^{7}$.

These adaptations can lead to a shoulder capsule repetitive microtrauma. Excessive external rotation occurs due to continuous strains on the anterior shoulder capsule region during the late cocking phase of the tennis serve $\mathrm{p}^{7}$ This repetitive stress may cause anterior instability in the shoulder, which, in turn, generates an increase in the external rotation. Deficits in internal rotation ROM occur due to the contraction of the posterior and inferior parts of shoulder capsule that suffer microtraumas in the follow-through phase of the tennis serve ${ }^{3}$.

Moreover, the athlete requires his external shoulder rotators (eccentrically required) in the follow-through phase of the tennis serve to slow down his arm. At that moment, these muscles under healthy conditions can absorb all arm energy and slow down the internal rotation movement ${ }^{15,16,17}$. However, some athletes do not have this essential capacity, and the arm energy is also absorbed by the posterior and inferior region of the shoulder capsule. This situation predisposes these athletes to injuries in the rotator cuff muscles and in the joint capsule, which generates pain and posterior shoulder tightness ${ }^{5,7}$. There are some studies indicating that rotator cuff strength is directly related to glenohumeral joint co-adaptation and protection, as well as with correct sports gestures ${ }^{11,16}$. For the correct function and protection of the shoulder during the tennis practice, the athletes require a good strength ratio between the internal and external shoulder rotator muscles ${ }^{5,16,17}$. Thus, the rotator cuff of tennis players has become a relevant item to be evaluated to understand shoulder pain and to prevent future injuries in these athletes.

Thus, the main objective of this study was to evaluate the posterior shoulder tightness and rotator cuff strength in the painful and nonpainful shoulders of skilled amateur tennis players. We hypothesised that players who have experienced shoulder pain would present a reduction in internal shoulder rotation, present an increase in external shoulder rotation, and demonstrate posterior shoulder tightness, as well as rotator cuff strength reduction.

\section{Method}

\section{Subjects}

Forty-nine male amateur tennis players, participating in State Federation championships in São Paulo, Brazil, during 2009 and 2011, who were between 19 and 33 years old (average \pm SD age, $26.2 \pm 3.9$ years old; height, $177.3 \pm 0.1 \mathrm{~cm}$; and body mass, $75.4 \pm 5.4 \mathrm{~kg}$ ), were allocated into 2 groups in agreement with the presence of pain or absence of pain in their dominant shoulders, the Painful Group (PG, n=27) and the Control Group (CG, $n=22)$, respectively. All tennis players in both groups evaluated must have had at least 8 years of tennis practice and played between 8 and 12 hours per week (training or playing) with or without shoulder pain in the dominant side.

The subjects included in the CG could not complain of shoulder pain in the dominant side during and after the matches. They also could not report feeling pain in the following shoulder tests: Hawkins-Kennedy ${ }^{18}$, $\mathrm{O}^{\prime}$ Brien $^{19}$, and Shoulder Internal Impingement ${ }^{20}$. On the other hand, the subjects included in the PG all complained of dominant shoulder pain during and after the matches and also were required to have positive signs in the shoulder tests described above. The exclusion criteria were the same for both groups: prior history of orthopaedic surgery or fractures in the upper limbs and/or cervical region as well as systemic diseases and/or metabolic disorders. All the 
assessments were made before the games and during a championship. Thus, we most likely excluded some tennis players that felt so much pain that they could not join the championship. Therefore, the subjects in the PG most likely did not feel an excessive level of pain that prevented tennis practice.

The authorisation to use data, clinical information and images of the athletes involved in this study was obtained via a written informed consent agreement signed by all of the athletes. Before the evaluations began, approval was also obtained from the Ethics Committee of the Irmandade da Santa Casa de Misericórdia de São Paulo, São Paulo, SP, Brazil (number 266/09).

\section{Procedures}

The first evaluator conducted an interview with the potential participants to acquire all pertinent information for the study. During this interview, an author-created questionnaire was used to acquire data about age, height, weight, dominant shoulder, presence of pain, playing experience (years) and practice during the week (hours). This questionnaire included the visual analogue scale (VAS) for pain evaluation, when pain was present, as widely used in other studies of shoulder pain ${ }^{21}$. The HawkinsKennedy ${ }^{18}$, O'Brien ${ }^{19}$, and Shoulder Internal Impingement test ${ }^{20}$ were performed on all athletes by the first evaluator.

The VAS was composed of a line that was $100 \mathrm{~mm}$ in length without graduations to avoid affecting the reliability of the measurements. Zero (0) was the beginning number on the left final point and indicated an absence of any symptoms of pain, whereas the right final number (100) indicated the worst imaginable pain. Clearly, pain is an important item to be evaluated and, therefore, the subjects were evaluated with the VAS. This scale was used because it is considered to be a highly reliable, easy and fast instrument to use for such an evaluation goal ${ }^{22,23}$.

\section{Posterior shoulder tightness and shoulder range of motion evaluations}

The posterior shoulder tightness evaluations were realised in agreement with the Myers et al. method ${ }^{10}$. The athletes were positioned in supine decubitus by the second evaluator (blinded), with the shoulder to be evaluated at a $90^{\circ}$ angle of abduction and neutral rotation. The second evaluator kept the elbow at a $90^{\circ}$ angle of flexion and instructed the subject to keep the arm relaxed.

During the tests, the second evaluator stabilised the athlete's scapula using the thenar and hypothenar regions with his hand on the scapula lateral edge, while using the other hand to move the athlete's arm in horizontal adduction. With a minimal movement of the scapula in the thenar and hypothenar regions from his hand, the athlete's arm was fixed by the second evaluator, whereas the third (blinded) evaluator measured the range of motion with the goniometer. The goniometer's axis was placed over the acromionclavicular joint. The goniometer's fixed arm was placed parallel to the ground, and the goniometer's mobile arm was directed to the lateral epicondyle of the athlete's humerus (Figure 1). These procedures were performed for the dominant and nondominant shoulders. Three measurements were taken for each shoulder, and the averages were also calculated. According to Myers et al. ${ }^{10}$, this measurement of posterior shoulder tightness is a relevant clinical indicator in overhead throwing athletes. Furthermore, it is an easy measurement to perform when the athlete is in a supine position. It is also a reliable method to assess posterior shoulder tightness ${ }^{10}$.

In addition to these measurements, shoulder passive ROM evaluations were performed for external and internal rotations. The athletes were positioned in supine decubitus by the second evaluator, with the shoulder to be evaluated at a $90^{\circ}$ angle of glenohumeral abduction. The second evaluator also moved the arm passively into external and internal rotation. The third evaluator positioned

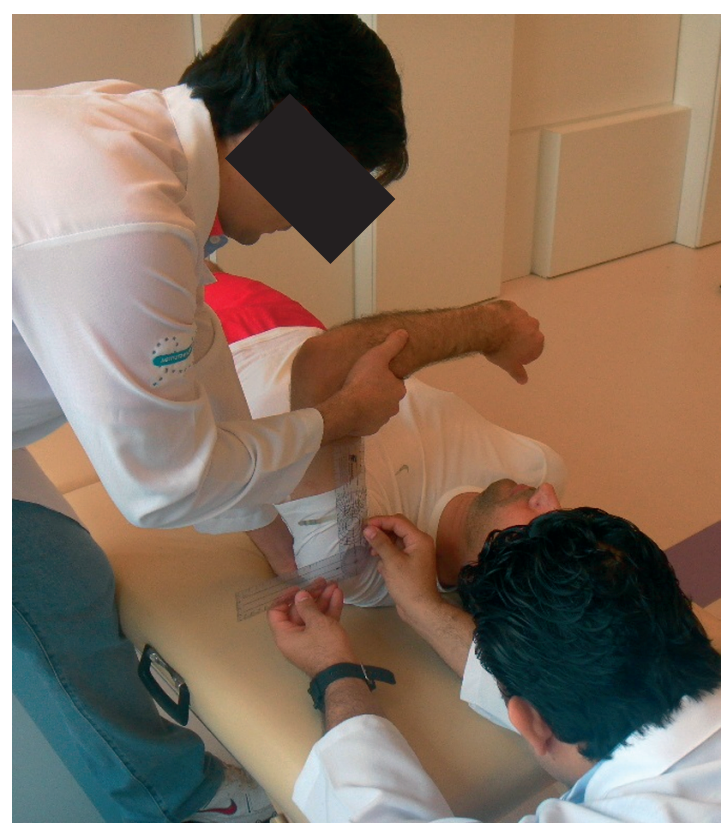

Figure 1. Assessment of the posterior shoulder capsule tightness. 
the goniometer and performed the measurement of shoulder internal and external rotation. The axis of the goniometer was placed over the athlete's olecranon, the goniometer's fixed arm was aligned parallel to the ground, and the movable arm was placed parallel to the athlete's ulnar lateral margin. During these tests, a manual stabilisation of the scapulo-thoracic joint was performed by the second evaluator, with the force applied over the coracoid process and the anterior acromion. Muir and colleagues demonstrated that this is a reliable way to measure shoulder $\mathrm{ROM}^{24}$, and the manual stabilisation avoided scapula compensatory movements (protraction and elevation) ${ }^{25}$.

\section{Rotator cuff strength evaluations}

A handheld Lafayette dynamometer (Lafayette Instrument Company, Lafayette, IN, USA) was used to measure strength. The strength test was realised in agreement with the method of Donatelli and colleagues ${ }^{15}$. The athletes were positioned in supine decubitus, with the shoulder to be evaluated at a $30^{\circ}$-angle horizontal adduction (with the elbow relaxed on a soft pillow to maintain this adduction), a $45^{\circ}$-angle shoulder abduction, and a $90^{\circ}$-angle elbow flexion. The fourth evaluator (blinded) positioned the subject and performed the strength assessment.

The dynamometer was positioned on the athlete's wrist region ( $2 \mathrm{~cm}$ below radial styloid process), on the dorsal wrist face to shoulder external rotator tests (Figure 2), and on ventral wrist face to shoulder internal rotator tests (Figure 3). During strength testing, we used 2 submaximal trials to familiarise the athletes with the tests positions. A 10-second rest interval was provided between the trials. After 10 more seconds, 2 maximal isometric contractions were performed at a standardised 5 seconds, with

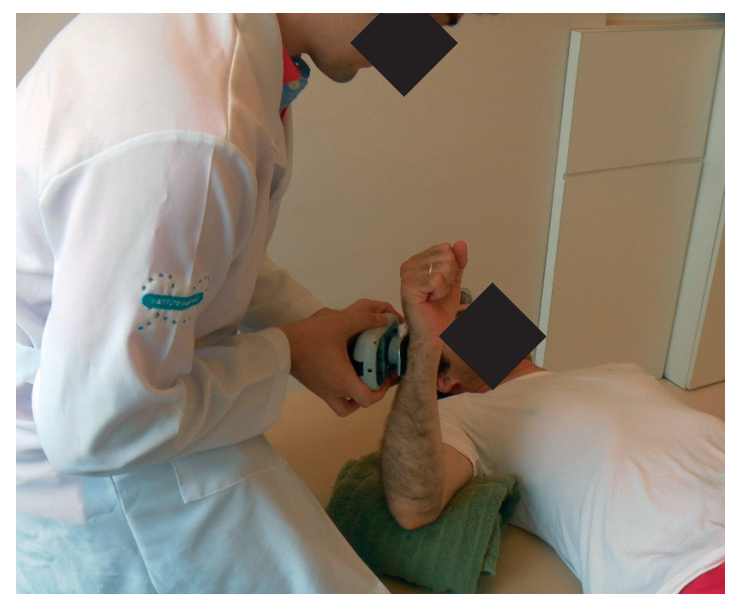

Figure 2. Assessment of the external rotators strength. a resting time of 30 seconds between maximal isometric contractions. For data analysis, the average values of the 2 trials with maximum effort were used $^{26}$. The same verbal commands were always used ("go, go, go") to encourage the athletes during the strength tests. The evaluation always followed this order: first the right shoulder (external and internal rotators) and finally the left shoulder (external and internal rotators). When the fourth evaluator observed any compensation during a test, the values were disregarded, and the test was repeated after 20 seconds of rest.

\section{Pilot study}

\section{Reproducibility}

The reproducibility of the data was also assessed in this study to prevent errors during the measurement of posterior shoulder tightness and external and internal rotation strength. We observed excellent intra-evaluators reliability. Therefore, the evaluators (2 and 3) involved in posterior shoulder tightness measured the dominant shoulder tightness of 5 athletes (average \pm SD age, $20.1 \pm 1.2$ years old; height $172.8 \pm 5.1 \mathrm{~cm}$; body mass, $72.1 \pm 4.8 \mathrm{~kg}$ ) twice. All athletes were evaluated in agreement with the process described above with a one-week interval between the two evaluations. The results indicated excellent intra-evaluator reliability, with intraclass correlation coefficients (ICC) of 0.98 .

Shoulder rotator cuff strength (external and internal rotators) was also measured by the fourth evaluator. This evaluator measured the dominant shoulder of 5 athletes (average \pm SD age, $20.1 \pm 1.2$ years old; height $172.8 \pm 5.1 \mathrm{~cm}$; body mass, $72.1 \pm 4.8 \mathrm{~kg}$ ).

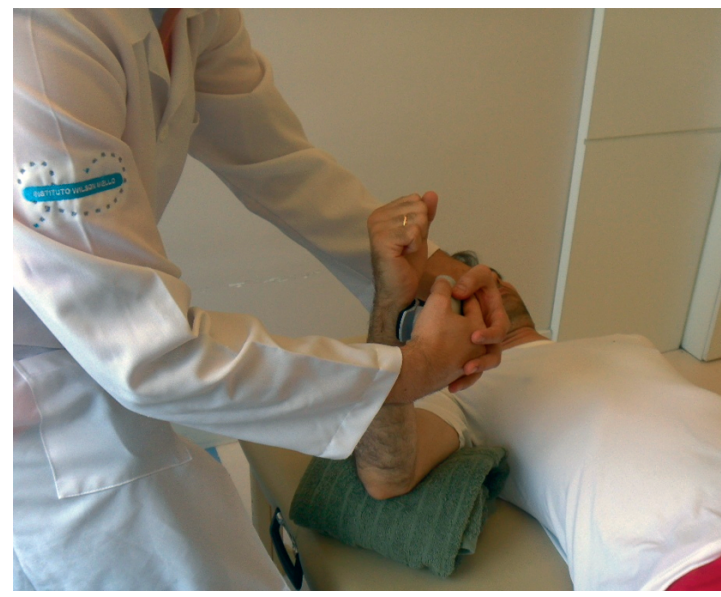

Figure 3. Assessment of the internal rotators strength. 
All athletes were evaluated in agreement with the process described above with a one-week interval between the two evaluations. The results indicated excellent intra-evaluator reliability, with intraclass correlation coefficients (ICC) of 0.95 for external shoulder rotators and 0.91 for internal shoulder rotators. These results indicated that the evaluators involved in this study were considered reliable and qualified to perform the evaluations proposed.

\section{Data analysis}

The results are expressed as the average \pm standard deviation, and SPSS 18.0 software was used to process the data. The Kolmogorov-Smirnov test (K-S) with correction using the Lilliefors test was used to verify data normality. A significance level of $95 \%$ was considered normal and an analysis of variance (ANOVA) was used to compare the groups. When significant differences were observed, the analysis was complemented by the Tukey test. Before these analyses, the strength data were normalised by body mass and also measured in kilograms using the following formula: ( $\mathrm{kg}$ strength/kg body weight) $\times$ $100^{27}$.

\section{Results}

Demographic data are provided in Table 1. The age, weight and height of the athletes were similar for both groups ( $p>0.05)$, and the VAS average \pm SD of the PG athletes was $4.5 \pm 1.2$. The posterior shoulder tightness analysis presented a significant difference $(\mathrm{p}<0.05)$ when data from the dominant shoulders of the PG was compared with the nondominant shoulders of the same group (intragroup analysis) and with the dominant and nondominant shoulders of the CG (intergroup analysis, $\mathrm{p}<0.05$ ), indicating that the dominant shoulders of the PG had greater posterior shoulder tightness than the other shoulders. The ROM, posterior shoulder tightness, strength and strength ratio (ER/IR) data are provided in Table 2.
The same results were observed with significant differences $(\mathrm{p}<0.05)$ when the same comparisons were performed for the external and internal shoulder rotation ROM, indicating that the dominant shoulders of the PG presented lower internal rotation ROM and larger external rotation ROM than the other shoulders, which revealed a displaced delta of ROM. The dominant shoulders of the $\mathrm{CG}$ displayed an increased external rotation compared with the nondominant shoulder of the same group $(\mathrm{p}<0.05)$.

When the strength analyses were performed, we only observed a significant difference $(\mathrm{p}<0.05)$ for the external rotation in the PG (dominant versus nondominant shoulders), indicating a weakness of the external rotators in the painful dominant shoulder. The comparisons of the strength ratio in the dominant shoulder of the PG (ER/IR) versus the strength ratio in the dominant shoulder of the CG displayed lower values (imbalance) in the dominant side of the PG $(\mathrm{p}<0.05)$. In contrast, the same comparisons of the nondominant shoulders (intergroup) did not detect such a difference $(\mathrm{p}>0,05)$.

\section{Discussion}

This was a cross-sectional study that evaluated pain (VAS), internal and external rotation range of motion (ROM), posterior shoulder tightness, and strength of asymptomatic and painful shoulders of skilled amateur tennis players. We observed an increase in dominant shoulder external rotation in both groups, but the dominant shoulder in the PG displayed a significantly larger external rotation than the other shoulders. The internal rotation ROM was significantly smaller in the dominant shoulder in the PG as compared with the other shoulders. Furthermore, we observed significant posterior shoulder tightness in the dominant shoulders in the $\mathrm{PG}$, in addition to weaker external rotation strength and a smaller strength ratio.

All data were collected during championships. Thus, the evaluations were performed quickly to

Table 1. Baseline characteristics (mean $\pm \mathrm{SD}$ ) of the athletes in each group.

\begin{tabular}{|c|c|c|c|}
\hline & Control group $(n=22)$ & Painful group $(n=27)$ & p-value \\
\hline Age (y) & $26.5 \pm 3.6$ & $25.9 \pm 4.1$ & $\mathrm{p}>0.05$ \\
\hline Weight $(\mathrm{kg})$ & $74.4 \pm 5.7$ & $76.2 \pm 5.1$ & $\mathrm{p}>0.05$ \\
\hline Height $(\mathrm{cm})$ & $176 \pm 0$ & $177 \pm 0$ & $\mathrm{p}>0.05$ \\
\hline Practice with pain (months) $\ddagger$ & 0 & $5.7 \pm 2.7$ & $\mathrm{p}<0.05$ \\
\hline VAS $(0-10) \ddagger$ & 0 & $4.5 \pm 1.2$ & $\mathrm{p}<0.05$ \\
\hline
\end{tabular}

GC. control group; GD. painful group; VAS. visual analog scale. $\ddagger$ Statistical difference between the 2 groups. 
Table 2. Athlete's amplitude of movement, posterior shoulder tightness, strength and strength ratio (mean $\pm \mathrm{SD}$ ).

Control group $(n=22) \quad$ Painful group $(n=27) \quad$ p-value

ROM

Dominant

External Rotation

Internal Rotation

Nondominant

External Rotation

Internal Rotation

Posterior Shoulder Tightness

Tightness

Dominant

Nondominant

Strength

Dominant

Internal Rotators

External Rotators

Nondominant

Internal Rotators

External Rotators

\section{Strength Ratio}

Dominant

Nondominant

$$
\begin{aligned}
& 97.3 \pm 4.6 \dagger+ \\
& 58.0 \pm 7.7 \dagger \neq \\
& 91.8 \pm 2.9 \dagger \\
& 64.1 \pm 4.8 \dagger
\end{aligned}
$$

$107.1 \pm 7.7 \dagger \dagger$

$49.2 \pm 8.6 \dagger \dagger$

$90.5 \pm 3.3 \dagger$

$65.4 \pm 11.1 \dagger$ $\mathrm{p}<0.05$

$\mathrm{p}<0.05$

$\mathrm{p}<0.05$

$\mathrm{p}<0.05$

$\begin{array}{lll}109.3 \pm 5.5 \dagger \dagger & 101.0 \pm 5.8 \dagger \dagger & \mathrm{p}<0.05 \\ 114.0 \pm 4.7 \dagger & 113.7 \pm 4.2 \dagger & \mathrm{p}<0.05\end{array}$

$$
\begin{aligned}
& 23.0 \pm 4.1 \\
& 19.0 \pm 3.8
\end{aligned}
$$

$$
\begin{aligned}
& 20.7 \pm 3.8 \\
& 20.5 \pm 3.4
\end{aligned}
$$

$$
24.0 \pm 3.4 \dagger
$$$$
17.9 \pm 2.9 \dagger
$$$$
22.0 \pm 3.5 \dagger
$$$$
21.4 \pm 2.9 \dagger
$$$$
0.74 \pm 0.1 \dagger \ddagger
$$

$0.98 \pm 0.1 \dagger$ $\mathrm{p}<0.05$

$\mathrm{p}<0.05$

$\mathrm{p}<0.05$

$\mathrm{p}<0.05$

$\mathrm{p}<0.05$

$\mathrm{p}<0.05$

$\dagger$ Statistical difference between dominant vs non dominant side (intragroup). $¥$ Statistical difference between groups (intergroup).

avoid compromising the athlete's participation. We chose a homogeneous group for the assessments (Table 1), and all the athletes participated in similar categories. The only difference between the groups was the presence or the absence of pain during the tennis matches and during the irritative tests ${ }^{18,19,20}$ that were performed by the first evaluator. In this context, we observed an average of $45 \mathrm{~mm}$ on the VAS in the dominant shoulder, which is more than the minimal clinically important difference in patients with shoulder disorders ${ }^{28}$. This observation indicates there was a significant difference in pain between the groups.

We observed excellent intra-evaluators reliability during the measurement of posterior shoulder tightness and external and internal rotation strength. Previous studies have demonstrated good intraevaluator reliability for the measurement of passive external and internal rotation ROM in supine position $^{24}$. The care taken prior to the start of the study ensured that our data were reliable. We observed a shorter internal rotation ROM in the dominant side of the PG as compared with the dominant side in the $\mathrm{CG}$ and the nondominant side in both groups. The external rotation ROM was increased in the dominant shoulder of the PG when compared to the other shoulders (dominant side in the CG and nondominant side in both groups). We also observed an increased external rotation ROM in the dominant shoulder of the $\mathrm{CG}$, which was shorter than in the PG but was significantly different from the nondominant sides in both groups. Previous studies have reported the same results of glenohumeral internal rotation deficit (GIRD) and external rotation gain $(E R G)^{5-7}$. Ellenbecker and colleagues observed an internal rotation deficit and an increased external rotation in tennis players and baseball pitchers, demonstrating similar deficits in different sports with overhead throwing movement ${ }^{29}$. In the present study, we observed an average ERG in the PG of $9.8^{\circ}$, as compared with the CG. The ERG was offset by a symmetrical loss of internal rotation (an average of $8.8^{\circ}$ ) and this pattern of modified ROM 
was previously demonstrated in overhead throwing shoulders ${ }^{5-7,29,30}$. Torres et al. studied the internal rotation ROM in tennis players and in swimmers ${ }^{31}$ and noted that tennis players had a larger GIRD than swimmers, but this GIRD was not offset by ERG, unlike in our findings.

We also observed changes in the posteroinferior capsule, as described by other authors ${ }^{13},{ }^{30-32}$, leading to posterior shoulder tightness, as first hypothesised by Papas et al. ${ }^{4}$. The overhead throwing motion leads to overstress in the posterior-inferior structures of the shoulder that cause repetitive microtraumas and, consequently tightness of the posterior-inferior portion of the capsule and rotator cuff muscles, generating GIRD ${ }^{7,30}$. We founded a significant posteroinferior capsule tightness in the dominant shoulder of PG, when compared to the dominant shoulder of CG and nondominant shoulder in both groups. Previous studies showed the deleterious effects of the posteroinferior capsule tightness, like Burkhart et al. ${ }^{33}$, hypothesizing that the posterior shoulder capsule leads to a posteriorsuperior shift in the humeral head during the latecocking phase of throwing. In the late-cocking phase, the biceps vector shifts posteriorly and twists at its base, maximizing peel-back forces and predisposing SLAP lesions. Muraki et al. ${ }^{6}$ showed in a cadaveric study that posteroinferior capsule tightness also leads to higher contact pressure under the subacromial arch and larger contact area, increasing the risk of rotator cuff injuries. Along with these biomechanical changes, humeral and glenoid retroversion has been cited like an adaptative mechanism that also contribute to posterior-inferior capsule tightness. Thomas et al. ${ }^{34}$ founded a significant positive correlation between humeral retroversion and posterior-inferior capsule thickness in collegiate baseball players.

When we analyze muscle strength, we found a significant deficit in external rotation in the dominant shoulder of PG as, compared with the dominant shoulder in CG and compared with nondominant shoulder in both groups. We didn't find any difference in internal rotation strength, in both sides and in both groups. This pattern of deficit is similar to the pattern found by Donatelli et al. ${ }^{15}$, where the authors analyzed the strength ratio of external rotation/internal rotation in healthy professional baseball pitchers. The authors founded a mean ratio of $83,9 \%$ in the dominant side and a mean ratio of $99,3 \%$ in the nondominant side. In this present study we founded a lower ratio in the dominant side of PG, showing that possibly the external rotation strength deficit may contribute to symptoms in the overhead throwing shoulder. Yildiz et al. ${ }^{16}$ studied the terminal range ratio of external/internal rotation in a ROM between $60^{\circ}$ and $90^{\circ}$ of internal rotation, similar to deceleration phase of throwing motion, showing that the ratio in this phase is about $103 \%$ (mean) in the dominant shoulder of healthy overhead athletes (volleyball, handball or tennis). The authors conclude that in this phase the external rotator must produce eccentric external rotation equal concentric internal rotation, to control the ending of the throwing motion. Fleisig et al. ${ }^{35}$ hypotheses that the deceleration phase is critical for the overhead movement, because the arm is brought to stop within a short period of time following a high velocity and high eccentric strength must be produced by the external rotators, which could predispose the muscles to tensile failure when an imbalance exist between external/internal rotators. Although we cannot compare isometric with isokinetic test, maybe it could be an explanation for our findings, where the dominant shoulder of the CG had a mean ratio of $82 \%$, producing more external rotation strength than the dominant shoulder in PG (mean of $74 \%, \mathrm{p}<0.05$ ), leading to joint protection during the throwing motion.

We had some limitations in our study, like the absence of scapular muscles tests and scapular dyskinesis evaluation. Scapular muscle weakness can make the scapula unstable, thereby making more difficult the strength evaluations of the rotator cuff $^{7,36,37}$. Another item that was not evaluated was muscle inhibition, because some studies indicated that pain can influence strength production in adjacent joint muscles ${ }^{38}$. Possibly, if neuromuscular electrical stimulation was applied during the strength tests, principally in athletes with shoulder pain, these athletes would show better strength results ${ }^{38,39}$.

\section{Conclusion}

The present study shows that skilled amateur tennis players with dominant shoulder pain and positive clinical findings of internal impingement and SLAP lesions have significant posterior shoulder tightness, GIRD, ERG and external rotation strength deficits, compared with control-group. These findings can help physical therapists that treat shoulder injuries in tennis players, besides show the functional deficits that can be found, creating preventive strategies for the shoulder injuries. 


\section{References}

1. Hjelm N, Werner S, Renstrom P. Injury profile in junior tennis players: a prospective two year study. Knee Surg Sports Traumatol Arthrosc. 2010;18:84550. PMid:20238099. http://dx.doi.org/10.1007/ s00167-010-1094-4

2. Pluim BM, Staal JB, Windler GE, Jayanthi N. Tennis injuries: occurrence, aetiology, and prevention. Br J Sports Med. 2006;40:415-23. PMid:16632572 PMCid:2577485. http://dx.doi.org/10.1136/bjsm.2005.023184

3. Van der Hoeven H, Kibler WB. Shoulder injuries in tennis players. Br J Sports Med. 2006;40:43540. PMid:16632575 PMCid:2577490. http://dx.doi. org/10.1136/bjsm.2005.023218

4. Papas AM, Zawacki RM, McCarthy CF. Rehabilitation of the pitching shoulder. Am J Sports Med. 1985;13:223-35. http://dx.doi.org/10.1177/036354658501300403

5. Thomas SJ, Swanik KA, Swanik CB, Kelly JD 4th. Internal rotation deficits affect scapular positioning in baseball players. Clin Orthop Relat Res. 2010;468:155157. PMid:19841995 PMCid:2865599. http://dx.doi. org/10.1007/s11999-009-1124-z

6. Muraki T, Yamamoto N, Zhao KD, Sperling JW, Steinmann SP, Cofield RH, et al. Effect of posteroinferior capsule tightness on contact pressure and area beneath the coracoacromial arch during pitching motion. Am J Sports Med. 2010;38:600-7. PMid:19966101. http://dx.doi. org/10.1177/0363546509350074

7. Burkhart SS, Morgan CD, Kibler WB. The disabled throwing shoulder: spectrum of pathology part III: the SICK scapula, scapular dyskinesis, the kinetic chain and rehabilitation. Arthroscopy. 2003;19:40420. PMid:12671624. http://dx.doi.org/10.1053/ jars.2003.50128

8. Laudner KG, Myers JB, Pasquale MR, Bradley JP, Lephart SM. Scapular dysfunction in throwers with pathologic internal impingement. J Orthop Sports Phys Ther. 2006;36:485-94. PMid:16881465.

9. Myers JB, Laudner KG, Pasquale MR, Bradley JP, Lephart SM. Scapular position and orientation in throwing athletes. Am J Sports Med. 2005;33:263-71. PMid:15701613. http://dx.doi.org/10.1177/0363546504268138

10. Myers JB, Oyama S, Wassinger CA, Ricci RD, Abt JP, Conley KM, et al. Reliability, precision, accuracy, and validity of posterior shoulder tightness assessment in overhead athletes. Am J Sports Med. 2007;35:1921-30. PMid:17609529. http://dx.doi. org/10.1177/0363546507304142

11. Lewis JS, Green AS, Dekel S. The aetiology of subacromial impingement syndrome. Physiotherapy. 2001;87:458-69. http://dx.doi.org/10.1016/S0031-9406(05)60693-1

12. Lewis JS, Green AS, Yizhat Z, Pennington D. Subacromial impingement syndrome: has the evolution failed us? Physiotherapy. 2001;87:191-8. http://dx.doi.org/10.1016/ S0031-9406(05)60605-0

13. Burkhart SS, Morgan CD, Kibler WB. Shoulder injuries in overhead athletes. The "dead arm" revisited. Clin Sports Med. 2000;19:125-58. http://dx.doi.org/10.1016/ S0278-5919(05)70300-8
14. Ramappa AJ, Hawkins RJ, Suri M. Shoulder disorders in the overhead athlete. Instr Course Lect. 2007;56:35-43. PMid:17472290.

15. Donatelli R, Ellenbecker TS, Ekedahl SR, Wilkes JS, Kocher K, Adam J. Assessment of Shoulder Strength in Professional Baseball Pitchers. J Orthop Sports Phys Ther. 2000;30:544-51. PMid:10994864.

16. Yildiz Y, Aydin T, Sekir U, Kiralp MZ, Hazneci B, Kalyon TA. Shoulder terminal range eccentric antagonist/ concentric agonist strength ratios in overhead athletes. Scand J Med Sci Sports. 2006;16:174-80. PMid:16643195. http://dx.doi.org/10.1111/j.1600-0838.2005.00471.x

17. Ludewig PM, Braman JP. Shoulder impingement: biomechanical considerations in rehabilitation. Man Ther. 2011;16:33-9. PMid:20888284 PMCid:3010321. http:// dx.doi.org/10.1016/j.math.2010.08.004

18. Caliş M, Akgün K, Birtane M, Karacan I, Caliş H, Tüzün F. Diagnostic values of clinical diagnostic tests in subacromial impingement syndrome. Ann Rheum Dis. 2000;59:44-7. PMid:10627426 PMCid:1752990. http:// dx.doi.org/10.1136/ard.59.1.44

19. O’Brien SJ, Pagnani MJ, Fealy S, McGlynn SR, Wilson JB. The active compression test: a new and effective test for diagnosing labral tears and acromioclavicular joint abnormality. Am J Sports Med. 1998;26:610-13. PMid:9784804.

20. Edelson G, Teitz C. Internal impingement in the shoulder. J Shoulder Elbow Surg. 2000;9:308-15. PMid:10979527. http://dx.doi.org/10.1067/mse.2000.105449

21. Littlewood C, Ashton J, Chance-Larsen K, May S, Sturrock B. Exercise for rotator cuff tendinopathy: a systematic review. Physiotherapy. 2012;98(2):1019. PMID:22507359. http://dx.doi.org/10.1016/j. physio.2011.08.002

22. Price DD, MsGrath PA, Rafii A, Buckingham B. The validation of visual analogue scales as ratio scale measures for chronic and experimental pain. Pain. 1983;17:45-56. http://dx.doi.org/10.1016/0304-3959(83)90126-4

23. Saccol MF, Gracitelli GC, Da Silva RT, Laurino CF, Fleury $\mathrm{AM}$, Andrade Mdos S, et al. Shoulder functional ratio in elite junior tennis players. Phys Ther Sport. 2010;11:8-11. http://dx.doi.org/10.1016/j.ptsp.2009.11.002

24. Muir SW, Corea CL, Beaupre L. Evaluating change in clinical status: reliability and measures of agreement for the assessment of glenohumeral range of motion. $\mathrm{N}$ Am J Sports Phys Ther. 2010;5:98-110. PMid:21589666 PMCid:2971638.

25. Ellenbecker TS, Roetert EP, Piorkowski PA, Schulz DA. Glenohumeral joint internal and external rotation range of motion in elite junior tennis players. J Orthop Sports Phys Ther. 1996;24:336-41. PMid:8938599.

26. Magalhães E, Fukuda TY, Sacramento SN, Forgas A, Cohen M, Abdalla RJ. A comparison of hip strength between sedentary females with and without patellofemoral pain syndrome. J Orthop Sports Phys Ther. 2010;40:641-7. PMid:20508327.

27. Scoville CR, Arciero RA, Taylor DC, Stoneman PD. End range eccentric antagonist/concentric agonist strength 
ratios: a new perspective in shoulder strength assessment. J Orthop Sports Phys Ther. 1997;25:203-7. PMid:9048326.

28. Tashjian RZ, Deloach J, Porucznik CA, Powell AP. Minimal clinically important differences (MCID) and patient acceptable symptomatic state (PASS) for visual analog scales (VAS) measuring pain in patients treated for rotator cuff disease. J Shoulder Elbow Surg. 2009;18:927-32. PMid:19535272. http://dx.doi. org/10.1016/j.jse.2009.03.021

29. Ellenbecker TS, Roetert EP, Bailie DS, Davies GJ, Brown SW. Glenohumeral joint total rotation range of motion in elite tennis players and baseball pitchers. Med Sci Sports Exerc. 2002;34:2052-6. PMid:12471315. http://dx.doi. org/10.1097/00005768-200212000-00028

30. Myers JB, Laudner KG, Pasquale MR, Bradley JP, Lephart SM. Glenohumeral range of motion deficits and posterior shoulder tightness in throwers with pathologic internal impingement. Am J Sports Med. 2006;34:385-91. PMid:16303877. http://dx.doi. org/10.1177/0363546505281804

31. TorresRR, Gomes JL. Measurement of glenohumeralinternal rotation in asymptomatic tennis players and swimmers. Am J Sports Med. 2009;37:1017-23. PMid:19261903. http://dx.doi.org/10.1177/0363546508329544

32. Tyler TF, Nicholas SJ, Roy T, Gleim GW. Quantification of posterior capsule tightness and motion loss in patients with shoulder impingement. Am J Sports Med. 2000; 28:668-73. PMid:11032222.

33. Burkhart SS, Morgan CD, Kibler WB. The disabled throwing shoulder: spectrum of pathology, part I: pathoanatomy and biomechanics. Arthroscopy. 2003; 19:404-20. PMid:12671624. http://dx.doi.org/10.1053/ jars.2003.50128

34. Thomas SJ, Swanik CB, Kaminski TW, Higginson JS, Swanik KA, Bartolozzi AR, et al. Humeral retroversion and its association with posterior capsule thickness in collegiate baseball players. J Shoulder Elbow
Surg. 2012;21:910-6. PMid:21856177. http://dx.doi. org/10.1016/j.jse.2011.05.028

35. Fleisig GS, Andrews JR, Dillman CJ, Escamilla RF. Kinetics of baseball pitching with implications about injury mechanisms. Am J Sports Med. 1995;23:233-239. PMid:7778711. http://dx.doi. org/10.1177/036354659502300218

36. Merolla G, De Santis E, Campi F, Paladini P, Porcellini G. Supraspinatus and infraspinatus weakness in overhead athletes with scapular dyskinesis: strength assessment before and after restoration of scapular musculature balance. Musculoskelet Surg. 2010;94:119-25. PMid:21069487. http://dx.doi.org/10.1007/s12306-010-0082-7

37. Merolla G, De Santis E, Sperling JW, Campi F, Paladini P, Porcellini G. Infraspinatus strength assessment before and after scapular muscles rehabilitation in professional volleyball players with scapular dyskinesis. J Shoulder Elbow Surg. 2010;19:1256-64. PMid:20421171. http:// dx.doi.org/10.1016/j.jse.2010.01.022

38. Reinold MM, Macrina LC, Wilk KE, Dugas JR, Cain EL, Andrews JR. The effect of neuromuscular electrical stimulation of the infraspinatus on shoulder external rotation force production after rotator cuff repair surgery. Am J Sports Med. 2008;36:2317-21. PMid:18757763. http://dx.doi.org/10.1177/0363546508322479

39. Hopkins JT, Ingersoll D. Arthrogenic muscle inhibition: a limiting factor in joint rehabilitation. J Sports Rehabil. 2000;9:135-59.

\section{Correspondence}

\section{Freddy B. Marcondes}

Rua José Rocha Bonfim, 214, Ed. Chicago

Condomínio Praça Capital, Jardim Santa Genebra

CEP 13080-650, Campinas, SP, Brasil

e-mail: freddy@iwmello.com.br 
